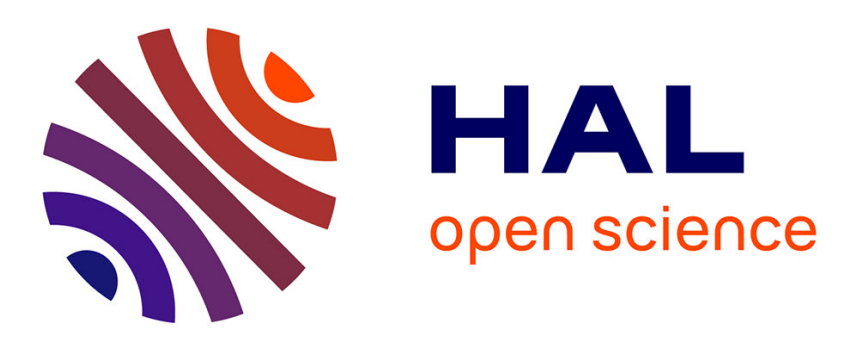

\title{
Proposal of a new erythemal UV radiation amplification factor
}

\author{
A. Serrano, M. Antón, M. L. Cancillo, J. A. García
}

\section{To cite this version:}

A. Serrano, M. Antón, M. L. Cancillo, J. A. García. Proposal of a new erythemal UV radiation amplification factor. Atmospheric Chemistry and Physics Discussions, 2008, 8 (1), pp.1089-1111. hal-00303262

\section{HAL Id: hal-00303262 \\ https://hal.science/hal-00303262}

Submitted on 23 Jan 2008

HAL is a multi-disciplinary open access archive for the deposit and dissemination of scientific research documents, whether they are published or not. The documents may come from teaching and research institutions in France or abroad, or from public or private research centers.
L'archive ouverte pluridisciplinaire HAL, est destinée au dépôt et à la diffusion de documents scientifiques de niveau recherche, publiés ou non, émanant des établissements d'enseignement et de recherche français ou étrangers, des laboratoires publics ou privés. 
Atmos. Chem. Phys. Discuss., 8, 1089-1111, 2008

www.atmos-chem-phys-discuss.net/8/1089/2008/

(C) Author(s) 2008. This work is licensed

under a Creative Commons License.

Proposal of a new erythemal radiation amplification factor

A. Serrano et al.

\section{Proposal of a new erythemal UV radiation amplification factor}

\section{A. Serrano, M. Antón, M. L. Cancillo, and J. A. García}

Departamento de Física, Universidad de Extremadura, Badajoz, Spain

Received: 29 November 2007 - Accepted: 11 December 2007 - Published: 23 January 2008

Correspondence to: A. Serrano (asp@unex.es)

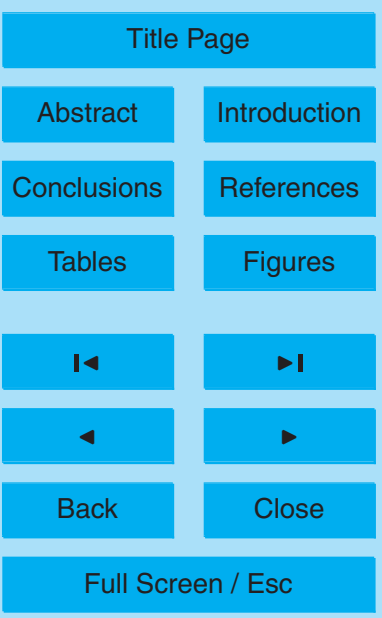

Printer-friendly Version

Interactive Discussion 


\section{Abstract}

This work is aimed to propose a natural expansion of radiation amplification factor (RAF) for erythemal irradiance to consider all solar zenith angles cases together. In this direction, the article analyzes the relationship between measurements of UV ery5 themal radiation (UVER) recorded at Badajoz (Spain) and the total ozone column estimated by the instrument TOMS/NASA for that location during the period February 2001-December 2005. The new RAF parameter is formulated by power equation using slant ozone and UVER atmospheric transmissivity values. Thus, reliable values of this parameter have been reported. These values could serve as a new relevant index for comparison with other studies and model's result.

The new RAF is calculated with measurements recorded during completely clear cases using clearness index values higher than 0.75 . The RAF value was $1.35 \pm 0.01$, it is to say, when the slant ozone amount decreases 1\% at Badajoz, UVER atmospheric transmissivity values and, therefore, UVER surface values approximately increase $1.35 \%$. This result emphasizes the interest of measuring and monitoring simultaneous measurements of UV radiation and stratospheric ozone even for mid-latitudes. The influence of total ozone amount and cloudiness changes on new RAF values is analyzed. Cloud-free conditions allow to study the ozone influences while cloud effects are analyzed with all data by means of monthly average of slant ozone and UVER atmospheric transmissivities values.

\section{Introduction}

It is well known that ozone is one main attenuation source for the ultraviolet (UV) radiation coming from the sun. Variations in stratospheric ozone immediately affect the amount of UV radiation reaching the earth's surface. During the last three decades, the reduction in stratospheric ozone has resulted in increased UV radiation observed at earth's surface in both hemispheres. Regarding the UVER (ultraviolet erythemal

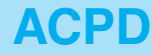

$8,1089-1111,2008$

Proposal of a new erythemal radiation amplification factor

A. Serrano et al.

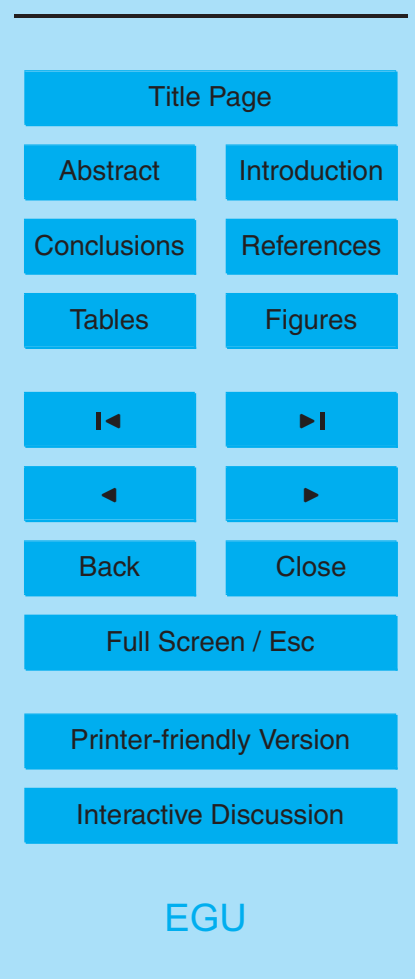


radiation), this increase was estimated to be about $4 \%$ in summer/fall and $7 \%$ in winter/spring respect to 1970's values at Northern Hemisphere mid-latitudes (WMO, 2002).

This increase in UV radiation at earth's surface may have detrimental consequences 5 for human health. Thus, according to the study by Lopez-Abente et al. (1996), during the period 1978-1992 the melanoma (the most dangerous type of skin cancer) annually rose about $5 \%$ in Spain. Other harmful effects have been also observed, such as an increase in the incidence and severity of cataracts and of the weakening of the immune system response (UNEP, 1998). In addition, the increase in UVER values associated 10 with ozone depletion could have important consequences for living organisms. Thus, adverse effects of this increment in plant growth, photosynthesis and aquatic ecosystems (the major contributor to the earth's biomass) may be substantial (Diffey, 1991). Therefore, it is needed to quantify the relationship between stratospheric ozone and UV radiation reaching the earth's surface.

15 The sensitivity of the surface UV radiation to stratospheric ozone changes is strongly wavelength-dependent, especially at shorter wavelengths where ozone absorption is increasing with decreasing wavelengths (Bais et al., 1993). Thus, only a small range of UV spectral radiation measured at surface is affected strongly by stratospheric ozone. This radiation band is known as UV-B (wavelengths from 280 to $315 \mathrm{~nm}$ ). Moreover, from the point of view of biological effectiveness this band is the most important since solar radiation in that region has enough energy to induce notable effects. Thus, for example, the erythemal weighting function used in this paper to obtain UVER values presents its maximum at $297 \mathrm{~nm}$ (McKinlay and Diffey, 1987). Therefore, the UVER data show a high sensitivity to ozone changes.

25 The impact of ozone depletion on UVER values is frequently expressed by means of the erythemal UV Radiation Amplification Factor (RAF) defined as the percentage increase in UVER that would result from a 1\% decrease in the column amount atmospheric ozone (McKenzie, 1991). For that aim, the RAF was proposed and has become a widely used standard index during last years (McKenzie, 1991; Madronich,

\section{Proposal of a new erythemal radiation amplification factor}

A. Serrano et al.

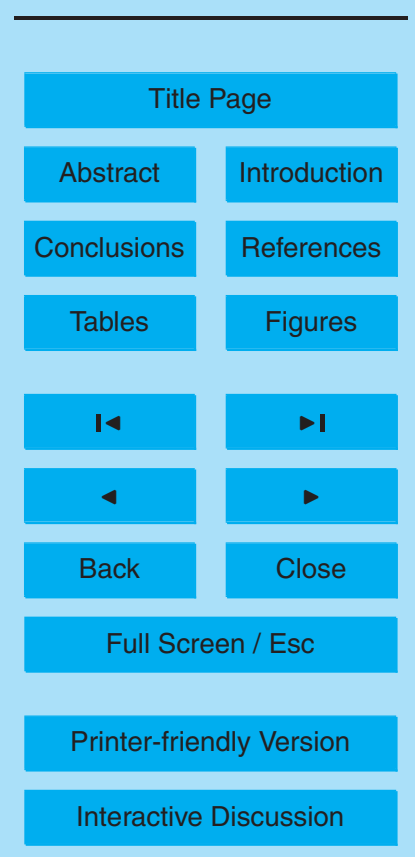

EGU 
1993; Bodhaine et al., 1997; Madronich et al., 1998; Dubrovsky, 2000; Zerefos, 2002).

Although it is a standard and well-considered index, it has some drawbacks which limit its calculation at many stations. Some of these limitations result from the need to measure at a fixed solar zenith angle. This requirement drastically reduces the 5 number of measurements available for its calculation. Also, it avoids the possibility of using measurements of total ozone provided by sun-synchronous satellites since such satellites use to over-pass a certain station at a fixed solar local time which, due to the daily variation in solar declination, result in different solar zenith angles. Thus, the computation of the RAF is reduced to the scarce stations where UV irradiance and 10 stratospheric ozone are simultaneously measured.

Therefore, in this paper an alternative more general definition of the RAF is given which includes measurements performed at different solar zenith angles. It allows the comparison of values obtained for different solar zenith angle and it allows the use of measurements of stratospheric ozone provided by satellites to be included in the RAF computation. Moreover, this paper analyzes the influence of total ozone amount and cloudiness changes on the new RAF parameter. For this objective, it is essential to have as many as possible simultaneous measurements of total ozone amount and UVER under different cloudiness conditions. In this work, 1531 data pairs measured during four years have been considered.

\section{Data}

UVER data were collected at the radiometric station in Badajoz belonging to the Department of Physics of the University of Extremadura. It was measured on a plane horizontal surface by a broadband UV-S-E-T erythematic radiometer manufactured by Kipp \& Zonen. This instrument is installed on the terrace of the building of the Department of Physics in the campus of the University of Extremadura $\left(38.99^{\circ} \mathrm{N}, 7.01^{\circ} \mathrm{W}\right.$, 199 m a.s.l.). The spectral response of this radiometer follows the Comission Internationale de l'Eclairage (CIE) spectrum (McKinlay and Diffey, 1987), which simulates the

\section{Proposal of a new erythemal radiation amplification factor}

A. Serrano et al.

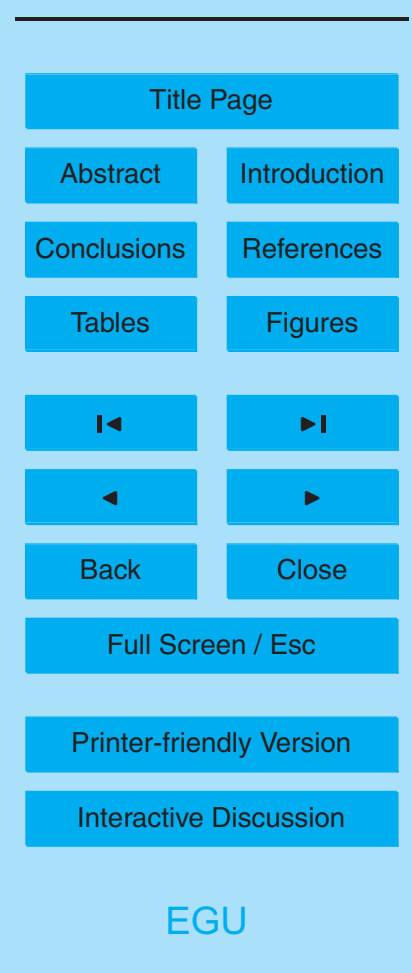


sensitivity of the human skin to develop a mild erythema when exposed to UV radiation. The radiometer output was converted into irradiance units using sound calibration coefficients obtained in field inter-calibration campaigns performed the years 2001, 2003, and 2005 with respect to a well-characterized and calibrated Brewer MK-II spectropho5 tometer (Cancillo et al., 2005). Finally, UVER data were sampled every ten seconds and averaged every minute in order to prevent from outliers and thus get representative data.

Additionally, remote sensing data from Total Ozone Mapping Spectrometer (TOMS) instrument were used. This remote sensor has been operative on board of two satel10 lites: Nimbus-7 (1978-1993) and Earth Probe (EP) (1996-2005). TOMS observes the backward scattered Earth solar radiance in several bands in the UV-A and UV$B$ spectral regions and measures the extraterrestrial solar irradiance in the same six wavelength channels. This information is used to estimate spatial distributed daily values of stratospheric ozone column amount expressed in Dobson Units (DU) (McPeters et al., 1998). TOMS total ozone and reflectivity data are provided by NASA Goddard Space Flight Center and data are available everyday via anonymous ftp service (ftp://toms.gsfc.nasa.gov). The horizontal spatial resolution is $1^{\circ}$ latitude $\times 1.25^{\circ}$ longitude. In general, there is a very good agreement between the TOMS ozone estimations and ground based measurements. Thus, McPeters et al. (1998) reported that the TOMS global ozone is about only $1 \%$ higher than the ground measurements in 30 mid-northern latitude stations. Other studies also showed a good agreement between satellite and ground based ozone data (Fioletov et al., 2002; Masserot et al., 2002).

In order to characterize the cloudiness condition, the atmospheric transmissivity for solar total horizontal irradiance, also named clearness index, $\left(k_{t}\right)$ was used. This variable is defined as the ratio of the total irradiance on a horizontal surface to the extraterrestrial solar irradiance on a horizontal surface. Clearness index has been previously shown to be a useful estimation of cloud cover (Foyo-Moreno et al., 1999; Cañada et al., 2000; Murillo et al., 2003). An important advantage of this study is that the cloudiness index measurements are simultaneous with UVER measurements, since total ir-

\section{Proposal of a new erythemal radiation amplification factor}

A. Serrano et al.

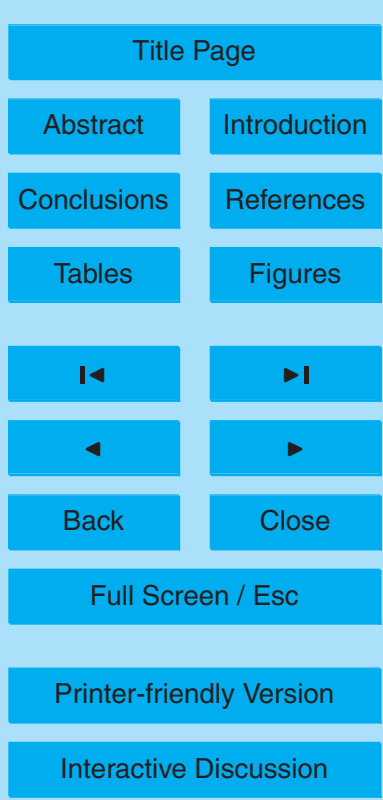


radiance values are recorded by a CM-6B pyranometer installed beside the broadband UV-erythematic radiometer and registered by the same data-logger.

In order to relate the ground data to remote sensing data, UVER data and cloudiness index used in this paper correspond to averages for values recorded between 5 10:30 and 11:30 UTC hour. This interval includes all TOMS pass over Badajoz. Accordingly, solar zenith angles were also averaged for the same time interval. Thus, 1531 simultaneous data of UVER, cloudiness index and ozone were selected for this study, extending from 1 February 2001 to 31 December 2005. These cases correspond to different solar zenith angles, being all of them lower than $66^{\circ}$. This fact is remarkable since UVER values are higher for low solar zenith angles.

\section{Methodology}

\subsection{Theoretical background}

The concept of the Radiation Amplification Factor, also called sensitivity by Madronich (1992) or magnification factor by Bais et al. (1993), have been widely used to relate the relative ozone depletion with the relative increase in different biologically effective UV irradiances. Thus, from UV radiation data, this factor have been estimated, for example, for skin cancer-effective irradiance (Scotto et al., 1988), immune suppression-effective irradiance (De Fabo, et al., 1990), DNA damage-effective irradiance and phytoplanktoneffective irradiance (Lubin et al., 1992). For many other biologically effective UV irradiances the RAF values can be found in the UNEP report (1998). The RAF concept for erythemal-effective UV irradiance was originally introduced by Mckenzie et al. (1991).

It is known that UVER values are related to total ozone amount $\left(\left[\mathrm{O}_{3}\right]\right)$ according to a power relationship (Madronich et al., 1998):

$$
\text { UVER }=C \cdot\left[\mathrm{O}_{3}\right]^{-\mathrm{RAF}} \text {, }
$$

where $C$ and RAF are two parameters which can be considered independent. Thus,

\section{Proposal of a new erythemal radiation amplification factor}

A. Serrano et al.

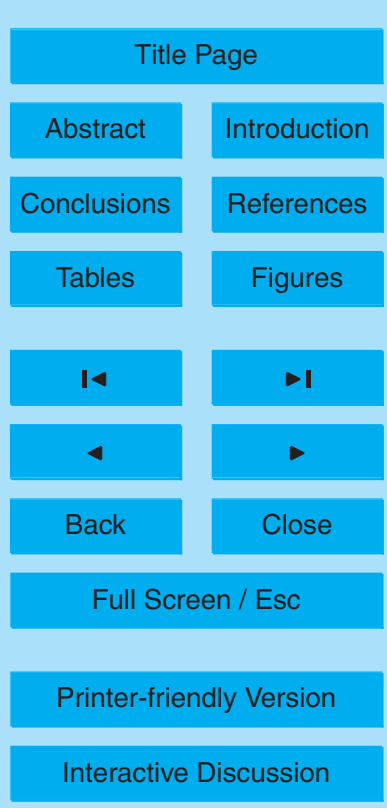


RAF is a useful indicator of the sensitivity of UVER to ozone changes. High RAF values indicate that the UVER values are strongly sensitive to changes in stratospheric ozone, while small RAF values indicate that UVER is less sensitive to ozone changes. It is called an amplification factor because it is usually greater than one. $C$ is related to other 5 atmospheric constituents which also scatter and absorb UVER, such as cloudiness, aerosols and tropospheric ozone. It represents the UVER amount at ground level in the case the stratospheric ozone value were $1 \mathrm{DU}$.

If $C$ is a constant Eq. (1) can be expressed as (Dubrovsky, 2000):

$$
\frac{\text { UVER }}{\text { UVER }^{*}}=\left(\frac{\left[\mathrm{O}_{3}\right]}{\left[\mathrm{O}_{3}\right]^{*}}\right)^{-\mathrm{RAF}}
$$

10 where $\left[\mathrm{O}_{3}\right] /\left[\mathrm{O}_{3}\right]^{*}$ is the relative change in the ozone column, and UVER/UVER ${ }^{*}$ is the corresponding relative increase in UVER (instantaneous or an a time-integrated basis e.g. daily, yearly). From this expression the RAF can be defined as (Madronich, 1993; Booth and Madronich, 1994):

$\mathrm{RAF}=-\frac{d L n(\mathrm{UVER})}{d L n\left[\mathrm{O}_{3}\right]}$.

15 Thus, a simple method for calculating the RAF is to perform a linear regression on a log-log plot. The resultant slope of this regression will be the RAF value (Bodhaine et al., 1997).

Finally, the Eq. (3) can be expressed as:

$\mathrm{RAF}=-\frac{\frac{\Delta U V E R}{U V E R}}{\frac{\Delta\left[\mathrm{O}_{3}\right]}{\left[\mathrm{O}_{3}\right]}}$,

which shows a linear relation between relative changes in ozone and relative changes in UVER values. This expression is used by several authors such as McKenzie et al. (1991), Bais et al. (1993), Chubarova and Nezval (2000) and Zerefos (2002).

\section{Proposal of a new erythemal radiation amplification factor}

A. Serrano et al.

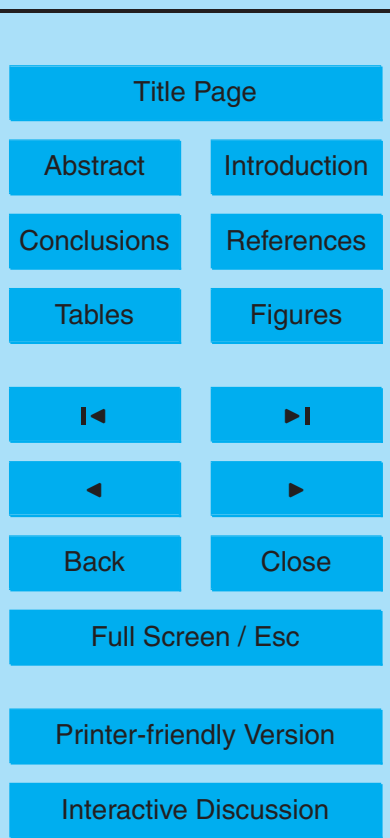

EGU 


\subsection{Procedure of new RAF calculation}

It is known that UVER highly varies at surface. The factors affecting the UVER at ground level are well recognized: solar zenith angle, cloudiness, total ozone, aerosols, surface albedo and altitude (WMO, 2002). Taking into consideration the number of

5 factors influencing UVER, in order to study its relationship just with total ozone, the cases are selected so as to have nearly constant values of the other factors.

Our broad band radiometer is a local observation and, therefore, altitude, latitude and longitude remain constant. Also, the ground albedo remains fairly constant along the year. In order to focus only on the effect of ozone, clear sky cases have been selected.

10 The clear sky cases are identified by a cloudiness index value higher than 0.75 . Several authors have used 0.65 as threshold (Kudish et al., 1993; Udo, 2000). In this study, to consider a higher threshold guarantees the cloud-free condition of the 489 cases selected ( $31 \%$ of the total). This high number of cloud-free cases shows the prevalence of clear conditions at Badajoz. The variation in UVER due to changes in zenith solar 15 angle is usually not analyzed, since most studies consider only measurements at fixed values of the solar zenith angle. However, in the present paper, UVER measurements are taken under different angles.

It is obvious that the UV radiation which reaches the earth's surface will depend on the ozone amount crossed along the actual slant path, more than on the ozone amount in the vertical column. Thus, to take into account the effects of this variable, the UVER values were normalized to its extraterrestrial values and the stratospheric ozone concentration was divided by cosine of the solar zenith angle. Therefore, a new $\mathrm{RAF}^{*}$ can be proposed according to the following expression:

$T=C \cdot Z^{-\mathrm{RAF}^{*}}$,

25 Where $T$ is the index of UVER atmospheric flux transmissivity averaged between 10:30 and 11:30 UTC hour. This index characterizes the atmospheric effect over UVER around TOMS over pass time and it is defined as UVER SURF $_{\text {UVER }}$ TOA where UVER $_{\text {SURF }}$ is the UVER values measured at surface and UVER $R_{\text {TOA }}$ is the UVER value 1096

8, 1089-1111, 2008

\section{Proposal of a new erythemal radiation amplification factor}

A. Serrano et al.

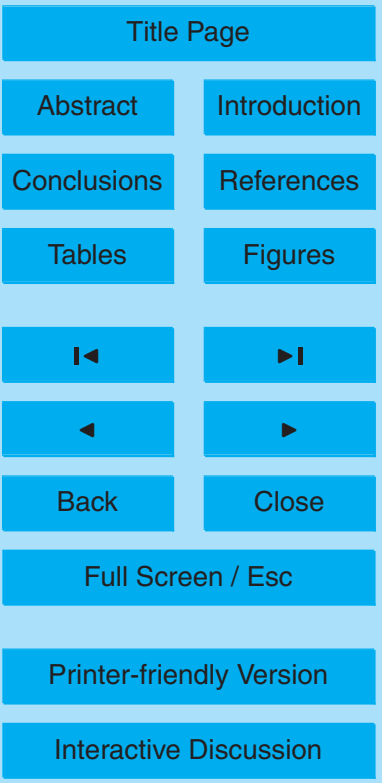

EGU 
on the top of the atmosphere on a horizontal surface. The extraterrestrial values are calculated based on the algorithms by Spencer (Iqbal, 1983) that depend on the day of year and the latitude of the location under study. $Z$ is the slant ozone column defined as $\left[\mathrm{O}_{3}\right] / \mu$, where $\mu$ is the cosine of the SZA corresponding to the average between 5 10:30 and 11:30 UTC hour. The new proposed expression 5 will be valid to UVER and total ozone values measured at different SZA.

In this work, to calculate the RAF parameter we followed an expression similar to Eq. (3). Therefore, the new RAF parameter that we propose is:

$\operatorname{RAF}^{*}=-\frac{d L n(T)}{d L n(Z)}$

10 This means that plotting $L n T$ versus $L n Z$ the points fall approximately on a straight line. In this way, the RAF* will be the slope of a straight-line fit on a log-log plot. For a given interval $\Delta\left[\mathrm{O}_{3}\right]$, the $\mathrm{RAF}^{*}$ characterizes the average variability of UVER transmissivity with slant ozone column in that ozone interval. Thus, doing the log-log plot for several intervals of total ozone column, it is possible to determine the influence of this variable on new RAF parameter. On the other hand, the influence of cloudiness changes on $\mathrm{RAF}^{*}$ parameter is studied through the monthly average of UVER transmissivity and slant ozone column values. These averages are calculated under different cloud conditions and, therefore, different $\mathrm{RAF}^{*}$ values are obtained.

\section{Results and discussion}

20 Firstly, seasonal variations in total ozone column and UVER values are analyzed during the period of measurements from February 2001 to December 2005.

On the one hand, total ozone column showed an average of 312 Dobson Unit (DU). The maximum and minimum ozone concentrations over Badajoz were 469 DU (16 March 2002) and 200 DU (10 January 2004), respectively. Figure 1 shows the total

\section{ACPD}

$8,1089-1111,2008$

Proposal of a new erythemal radiation amplification factor

A. Serrano et al.

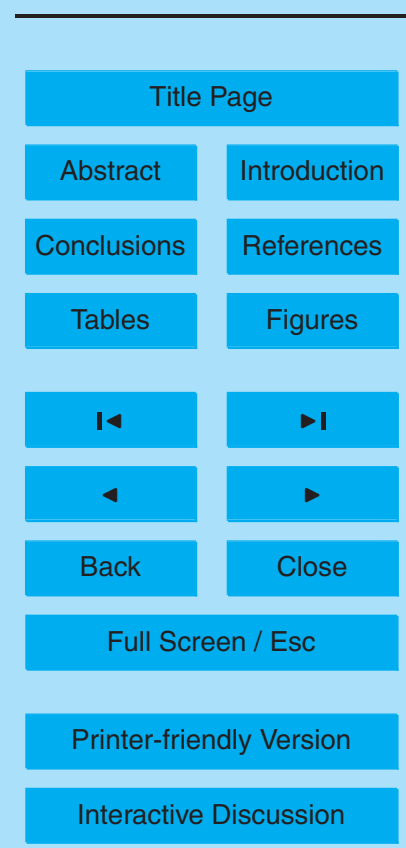


ozone seasonal cycle of the whole period. It can be seen that total ozone is maximum in spring and reaches its minimum in late autumn. This ozone variability can be explained in terms of the transport phenomena linked to frontal systems that affect Iberian Peninsula. Spring maximum are associated with the transport of northern air 5 masses, usually rich in columnar ozone content. Autumn minimum is associated with synoptic fronts that transport southern air masses, usually with lower ozone concentrations.

On the other hand, the seasonal variation of the UVER values around TOMS overpass basically follows a sinusoidal cycle controlled by variations of the solar zenith 10 angle and with important sharp spikes due to the effect of clouds (Fig. 2). Maximum and minimum of UVER values were observed as $209.47 \mathrm{~mW} / \mathrm{m}^{2}$ on 13 June 2002 and $3.50 \mathrm{~mW} / \mathrm{m}^{2}$ on 30 December 2002 , respectively. More details about the evolution of UVER values at ground level in Badajoz can be found in the paper by Serrano et al. (2006).

15 To analyze the relationship between total ozone and UVER, 489 cloud-free data pairs are considered. It is important to indicate the great number of cases due to the long measured period. For these cloud-free cases, monthly average of slant ozone column and UVER transmissivity values are shown in Fig. 3. The inverse correlation between these two variables is quite striking. Thus, UVER transmissivities are lower in winter months than summer months mainly due to the fact that the slant ozone column crossed by UV erythematic radiation is higher in winter than in summer. The error bars are calculated as the standard deviation of the monthly mean of data.

In order to analyze the UVER transmissivity variations produced by slant path ozone changes, the Fig. 4 shows the relationship between these two variables for cloud-free cases. The dependence of UVER transmissivity on slant ozone using a power law relationship is given by Eq. (5). It is remarkable that the experimental measurements notably follow to the theoretical curve. The correlation coefficient is 0.95 and the explained variance in UVER transmissivity due to slant path ozone is $91.1 \%$, which is an excellent result. Thus, a strong power relation can be seen with an explained variance

\section{Proposal of a new erythemal radiation amplification factor}

A. Serrano et al.

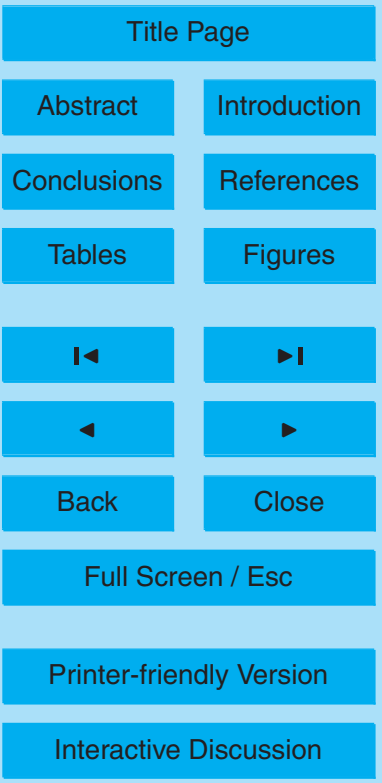

EGU 
very high. The rest of variance should be attributed to the variability of other factors not considered in this work, such as aerosols and tropospheric ozone.

Expression 6 is applied to estimate the RAF parameter. The value estimated was $1.35 \pm 0.01$. This value indicates that if there is a decrease of $1 \%$ in slant ozone value 5 at Badajoz then UVER transmissivity and, therefore, UVER values increase $1.35 \%$ approximately at the same time. High slant ozone changes produce evident non linear UVER transmissivity increases, for example a depletion of $20 \%$ produces a transmissivity increase of $35 \%$, different from the $27 \%$ obtained if a linear relation is used. Thus, the use of linear RAF expression may lead to serious underestimates of UVER values 10 when large changes of slant ozone values are involved. This agrees with the results of Booth and Madronich (1994). They found that the power form was superior to the linear form when both were compared with results from experimental data. The power law introduced in this work allow calculating a reasonably good RAF parameter from total ozone and UVER values measured at different solar zenith angle.

15 Several authors suggest that the erythemal UV RAF parameter is dependent with ozone changes (McKenzie, 1991; Bais et al., 1993; Fioletov et al., 2001). Our work agrees with those authors. Thus, to analyze the influence of total ozone changes on new RAF parameter, Eq. (5) is applied to slant ozone column and transmissivities values for cloud-free cases and two separated wide intervals of total ozone column.

20 Figure 5 shows the relationship between slant ozone column and UVER transmissivity differentiating ozone values lower and higher than 317 DU (median value). The RAF value for each one of two intervals is added in the figure. The new RAF parameter is considerably lower for high ozone values. This fact could be due to the ozone absorption is dominant at the short wavelengths. Thus, as the weight of the erythemal 25 action spectrum is more important for short wavelengths, this spectrum contributes proportionately less when the ozone amount increases (Michelleti et al., 2003).

Variations in cloud cover can have a strong influence on UVER values as seen in Fig. 6. Thus, the analysis of RAF parameter for cloudy cases is very interesting. However, the RAF parameter study is very difficult in those cloudy situations due to the

\section{Proposal of a new erythemal radiation amplification factor}

A. Serrano et al.

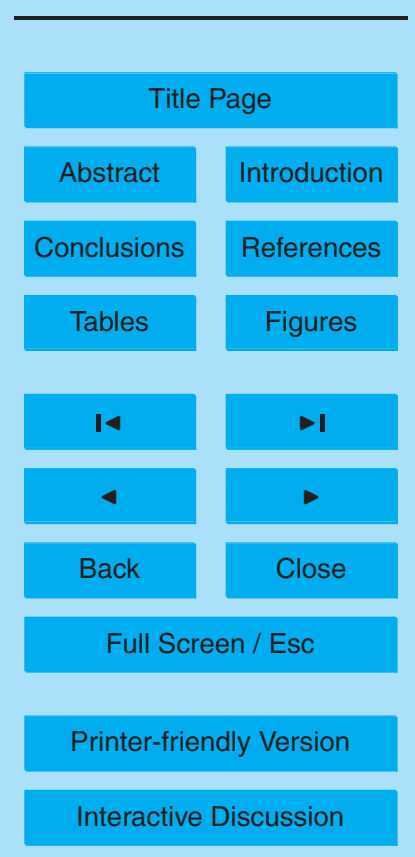


high variability of the optical properties of the atmosphere (Toure, 2003). In this work, to determine the influence of cloud effects on the RAF parameter, all data pairs (1531) of slant path ozone and UVER transmissivity measured during the whole period have been considered. From these data, monthly averages of two analyzed variables have 5 been calculated for four atmospheric conditions; clearness index $k_{t}>0.75$ (cloud-free cases), $k_{t}>0.50, k_{t}>0.25$ and $k_{t}>0.0$ (all cases). Figure 6 shows the relationship between monthly average of slant ozone column and UVER transmissivity values for the two extreme events. There is a significant correlation between the monthly average of slant ozone column and UVER transmissivity values even when all cases are 10 considered. Moreover, the four RAFs have been calculated according Eq. (6) and it can be observed in Table 1. This result indicates that, in spite of the large day-to-day variations in cloud cover, the ozone changes cause important fluctuations in monthly UVER measurements. It is remarkable that the new RAF parameter increase notably when the monthly average are calculated with a greater number of different sky conditions. Thus, new RAF parameter rises from 1.41 (only cloud-free cases considered in monthly averages) to 1.79 (all cases in monthly averages). It is difficult to explain why RAF parameter can reach high values when all type of sky conditions are considered but as UVER transmissivities are much lower in cloudy days than in cloud-free days this behaviour does not imply that the ozone depletion episode in cloudy days will have a stronger erythematic effect than the same ozone depletion episode in cloud-free days.

\section{Conclusions}

The present work contributes to the understanding of the relationship between ozone and UVER values measured at different solar zenith angles. Thus, a long period of these two variables (February 2001-December 2005), carried out in a continental site in South-West Spain, have been analyzed. The clearness index for the whole solar spectrum is the variable used for selecting different atmospheric conditions. Using a high number of UVER and total ozone data pairs measured on cloud-free days, we

\section{Proposal of a new erythemal radiation amplification factor}

A. Serrano et al.

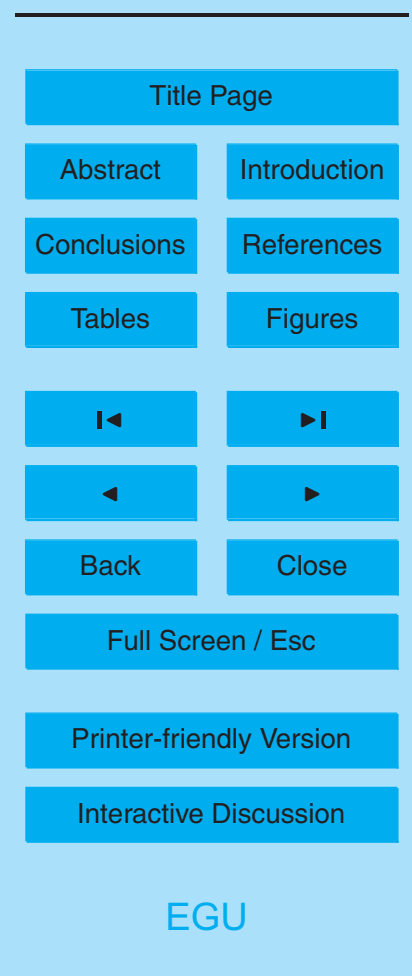


found that the UVER transmissivity shows a clear opposite behaviour than slant path ozone. Thus, summer months presented the highest UVER transmissivity values since the slant ozone amount reaches its lower values. Conversely, the behaviour was the opposite for winter months.

5 A new expression to obtain the erythemal UV RAF parameter was proposed. This equation explains around $91 \%$ of UVER atmospheric transmissivity variation due to the slant ozone changes in cloud-free days. Thus, the new RAF parameter introduced in this paper could be a good index capable of explaining the attenuation of UVER values due to the slant ozone changes.

10 This study showed the great influence of ozone and cloudiness changes on the new RAF parameter. On the one hand, the ozone influence was only studied from cloudfree data. We found that the new RAF value is notably affected by total ozone changes. Thus, there is an important increase of RAF parameter when high total ozone values are considered. This behaviour could be attributed to the weight of erythemal ac15 tion spectrum contributes proportionately less when the total ozone increases. The cloudiness influence was analyzed from all data. We found that monthly slant ozone changes affect notably to monthly UVER transmissivity measurements even when all atmospheric condition are considered. Moreover, when more cloudiness situations are considered, the RAF parameter increases its value. It is important to consider that this fact does not indicate that erythematic effects are more important when ozone changes occur in cloudy days.

In conclusion, this study provides reliable experimental RAF values that characterize the influence of slant ozone changes on UVER values measured at different solar zenith angles. Moreover, this new parameter proposed in this paper could serve as a 25 valid reference for comparison with values obtained in other locations for similar latitudes and with model results in order to a better understanding of the relationship between those two variables.

Acknowledgements. This work has been partially supported by MEC under project CGL200505693-C03-03/CLI, by the "Junta de Extremadura" under "Convenio para la creación y man-

\section{Proposal of a new erythemal radiation amplification factor}

A. Serrano et al.

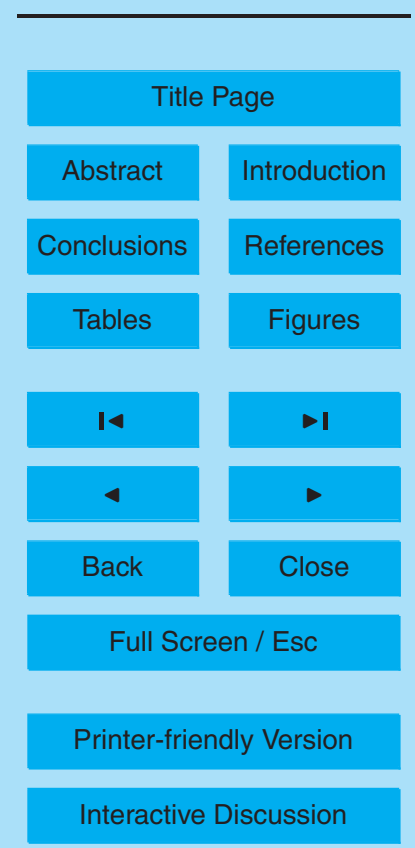

EGU 
tenimiento de una red de medida de la radiación solar ultravioleta en Extremadura", and by the “Consejería de Infractucturas y Desarrollo Tecnológico” (GRU07126).

\section{References}

Lopez-Abente, G., Pollán, M., Escolar, A., Errezola, M., and Abraira, V.: Atlas of cancer mortality and other causes of death in Spain 1978-1992, Fundación Científica de la Asociación Española Contra el Cáncer Madrid, avilable at: http://www2.uca.es/hospital/atlas92/www/ Atlas92.html (last access: 21 Jan 2008), 1996.

Bais, A., Zerefos, C., Meleti, C., Ziomas, I., and Tourpali, K.: Spectral measurements of solar UVB radiation and its relations to total ozone, so, and clouds, J. Geophys. Res., 98, 51995204, 1993.

Bodhaine, B., Dutton, E., Hofmann, D., McKenzie, R., and Johnston, P.: UV measurements at Mauna Loa: July 1995 to July 1996, J. Geophys. Res., 102, 19265-19273, 1997.

Booth, C. and Madronich, S.: Ultraviolet radiation in Antarctica: Measurements and biological effects, chapter Radiation amplification factors: Improved formulation accounts for large increases in ultraviolet radiation associated with Antarctic ozone depletion, 39-42, AGU, Washington, D.C., 1994.

Cañada, J., Pedrós, G., López, A., and Boscá, J.: Influences of the clearness index for the whole spectrum and of the relative optical air mass on UV solar irradiance for two locations in the Mediterranean area, Valencia and Córdoba, J. Geophys. Res., 105, 4799-4766, 2000.

Cancillo, M. L., Serrano, A., Antón, M., García, J. A., Vilaplana, J.M. , and de la Morena, B.: An improved outdoor calibration procedure for broadband ultraviolet radiometers, Photochem. Photobiol., 81, 860-865, 2005.

Chubarova, N. and Nezval, Y.: Thirty year variability of UV irradiance in Moscow, J. Geophys. Res., 105, 12529-12 539, 2000.

25 De Fabo, E., Noon, F., and Frederick, J.: Biologically effective doses of sunlight for inmune suppression at various latitudes and their relationship to changes in stratospheric ozone, Photochem. Photobiol., 52, 811-817, 1990.

Diffey, B.: Solar ultraviolet radiation effects on biological systems, Phys. Med. Biol., 36, 299328, 1991.

\section{Proposal of a new erythemal radiation amplification factor}

A. Serrano et al.

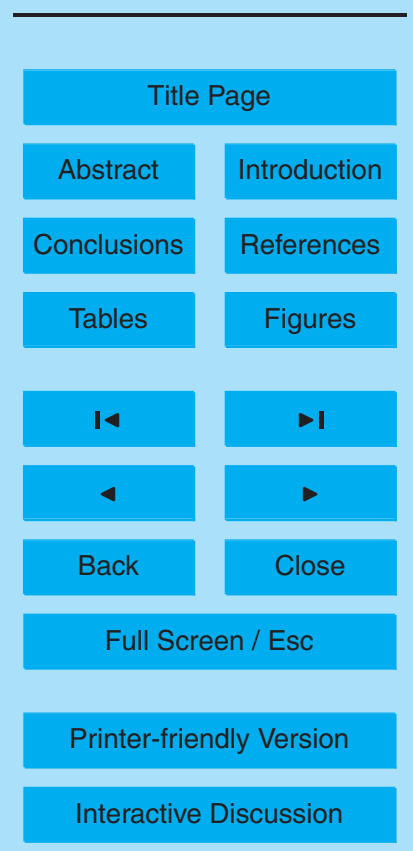


Dubrovsky, M.: Analysis of UV-B irradiances measured simultaneously at two stations in the Czech Republic. J. Geophys. Res., 105, 4907-4913, 2000.

Fioletov, V. E., Kerr, J. B., Wardle, D. I., Krotkov, N., and Herman, J.R.: Comparison of Brewer ultraviolet irradiance measurements with global ozone mapping spectrometer satellite retrievals, Opt. Eng., 41, 3051-3061, 2002.

Fioletov, V., Mcarthur, L., Kerr, J., and Wardle, D.: Long-term variations of UV-B irradiance over Canada estimated from Brewer observations and derived from ozone and pyranometer measurements, J. Geophys. Res., 106, 23 009-23 027, 2001.

Foyo-Moreno, I., Vida, J., and Alados-Arboledas, L.: A simple all weather model to estimate ultraviolet solar radiation (290-385 nm), J. Appl. Meteorol., 38, 1020-1026, 1999.

Iqbal, M.: An Introduction to Solar Radiation, Academic Press Canada, 1993.

Kudish, A., Wolf, D., and Machalv, Y.: Solar radiation data for Beer Sheva, Israel, Sol. Energy, 30, 33-37, 1993.

Lubin, D., Mitchel, B., Frederick, J., Alberts, A., Booth, C., Lucas, T., and Neuschuler, D.: A 15 contribution toward understanding the biopherical significance of Antarctic ozone depletion, J. Geophys. Res., 97, 7817-7828, 1992.

Madronich, S.: Implications of recent total atmospheric ozone measurements for biologically active ultraviolet radiation reaching the earth surface, Geophys. Res. Lett., 19, 37-40, 1992.

Madronich, S.: Environmental UV Photobiology, chapter The atmosphere and UV-B radiation $20 \quad$ at ground level, 1-39, Plenum, New York, 1993.

Madronich, S., McKenzie, R., Bjorn, R., and Caldwell, M.: Changes in biologically active ultraviolet radiation reaching the Earth's surface, J. Photoch. Photobio. B, 46, 5-19, 1998.

Masserot, D., Lenoble, J., Brogniez, C., Houet, M., Krotkov, N., and McPeters, R.: Retrieval of ozone column from global irradiance measurements and comparison with TOMS data, A

25 year of data in the Alps, Geophys. Res. Lett., 29(9), doi:10.1029/2002GL014823, 2002.

McKenzie, R., Matthews, W., and Johnston, P.: The relationship between erythemal UV and Ozone derived from spectral irradiance measurements. Geophys. Res. Lett., 18, 2269-2272, 1991.

McKinlay, A. and Diffey, B.: A reference spectrum for ultraviolet induced erythema in human skin, CIE Journal, 6, 21-27, 1987.

McPeters, R., Bhartia, P., Krueger, A., Herman, J., Wellemeyer, C., Seflor, C., Jaross, G., Torres, O., Moy, L., Labow, G., Byerly, W., Taylor, S., Swisler, T., and Cebula, R.: Earth Probe Total Ozone Mapping Spectrometer (TOMS) Data products User Guide, Technical Report

\section{Proposal of a new erythemal radiation amplification factor}

A. Serrano et al.

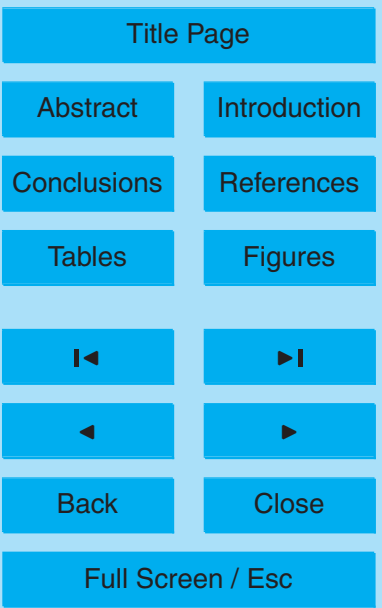

Printer-friendly Version

Interactive Discussion 
TP-1998-206895, NASA, 1998.

Michelleti, M., Piacentini, R., and Madronich, S.: Sensitivity of biologically active UV radiation to stratospheric ozone changes: Effects of action spectrum shape and wavelength range, Photochem. Photobiol., 78, 456-461, 2003.

5 Murillo, W., Cañada, J., and Pedrós, G.: Correlation between global ultraviolet (290-385 nm) and global irradiation in Valencia and Córdoba (Spain), Renew. Energ., 28, 409-418, 2003.

Scotto, J., Cotton, G., Urbach, F., Berger D., and Fears, T.: Biolgically effective ultraviolet radiation: Surface measurements in the Unites States, Science, 239, 762-764, 1988.

Serrano, A., Antón, M., Cancillo, A. M. L., and Mateos, V. L.: Daily and annual variations of erythemal ultraviolet radiation in Southwestern Spain, Ann. Geophys., 24, 427-441, 2006, http://www.ann-geophys.net/24/427/2006/.

Toure, M.: Exposition UV spectrale: Instrumentation et modelisation. PhD thesis, Université Joseph Fourier, Grenoble (France), 2003.

Udo, S.: Sky conditions at llorin as characterized by clearness index and relative sunshine, Sol. Energy, 69, 45-53, 2000.

UNEP: Environmental effects of ozone depletion: 1998 assessment, Technical report, United Nations Environmental Programme, 1998.

WMO: Scientific assessment of ozone depletion: 2002, global ozone research and monitoring project. Technical Report 47, World Meteorological Organization, 2003.

20 Zerefos, C.: Long-term ozone and UV variations at Thessalonika, Greece, Phys. Chem. Earth, 27, 455-460, 2002.

\section{Proposal of a new erythemal radiation amplification factor}

A. Serrano et al.

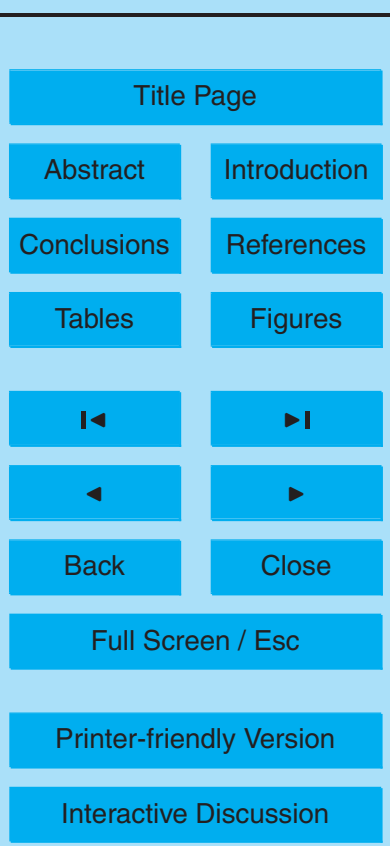




\section{ACPD}

$8,1089-1111,2008$

\section{Proposal of a new erythemal radiation amplification factor}

A. Serrano et al.

Table 1. New RAF parameter calculated for four $k_{t}$ intervals by monthly averages of UVER transmissivities and slant ozone amount.

\begin{tabular}{llll}
\hline$k_{t}$ interval & RAF & $N$ & $R^{2}$ \\
\hline $0-1$ & $1.79 \pm 0.05$ & 57 & 0.965 \\
$0.25-1$ & $1.65 \pm 0.04$ & 57 & 0.965 \\
$0.50-1$ & $1.50 \pm 0.04$ & 57 & 0.970 \\
$0.75-1$ & $1.41 \pm 0.03$ & 52 & 0.973 \\
\hline
\end{tabular}

Title Page

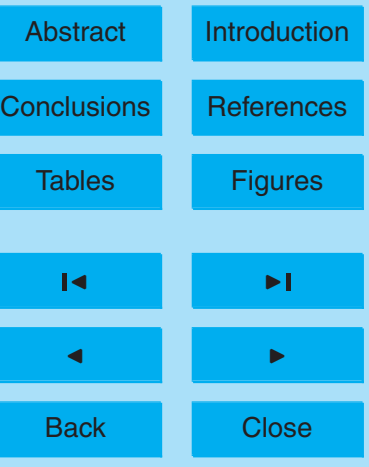

Full Screen / Esc

Printer-friendly Version

Interactive Discussion 


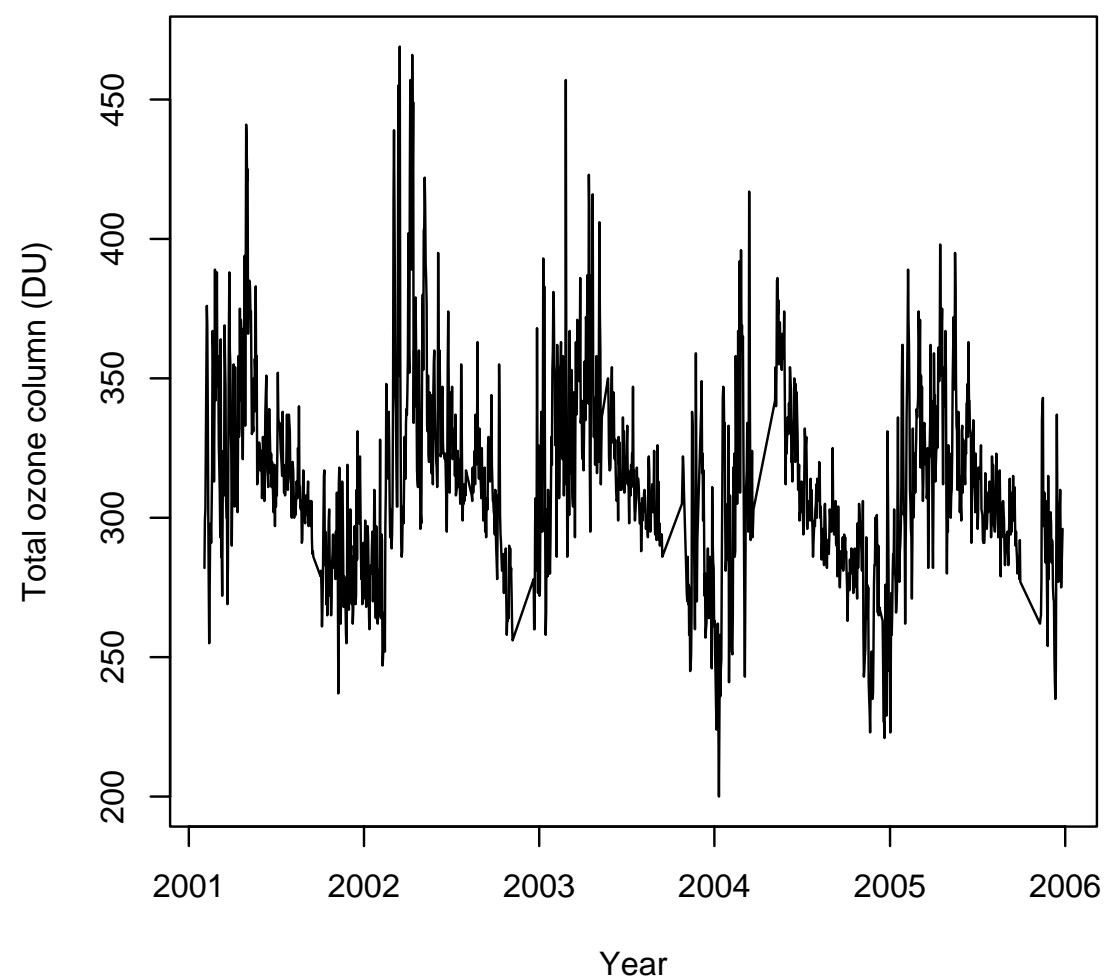

Fig. 1. Daily variation of TOMS/NASA total ozone column at Badajoz from February 2001December 2005.
8, 1089-1111, 2008

\section{Proposal of a new erythemal radiation amplification factor}

\section{A. Serrano et al.}

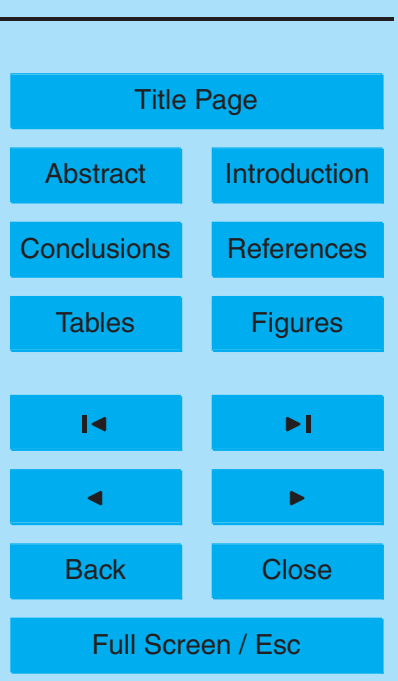

Printer-friendly Version

Interactive Discussion 


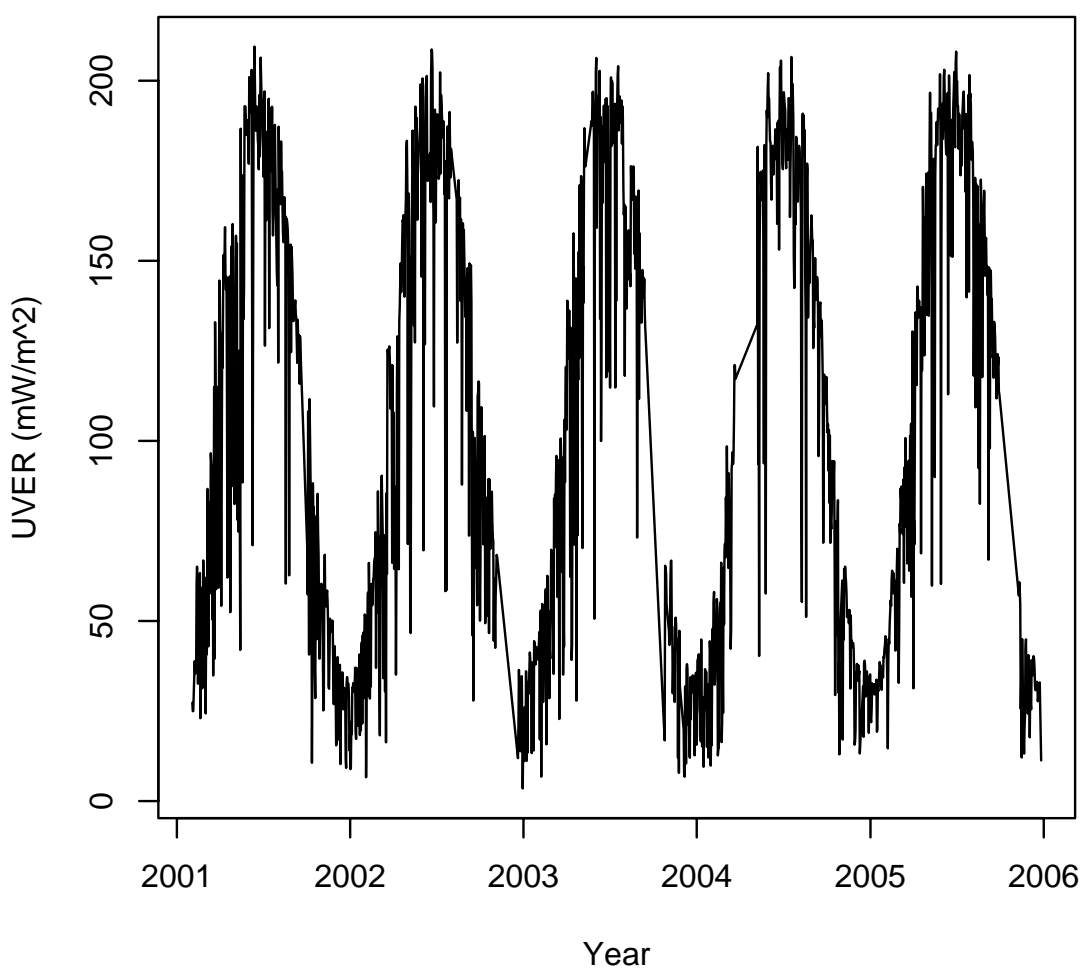

Fig. 2. Daily variation of the UVER values averaged between $10: 30$ and $11: 30$ UTC hours at Badajoz from February 2001-December 2005.
$8,1089-1111,2008$

\section{Proposal of a new erythemal radiation amplification factor}

\section{A. Serrano et al.}

Title Page

Abstract

Introduction

Conclusions

References

Tables

Figures

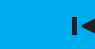

14

1

4

Back

Close

\section{Full Screen / Esc}

Printer-friendly Version

Interactive Discussion 


\section{ACPD}

\section{8, 1089-1111, 2008}

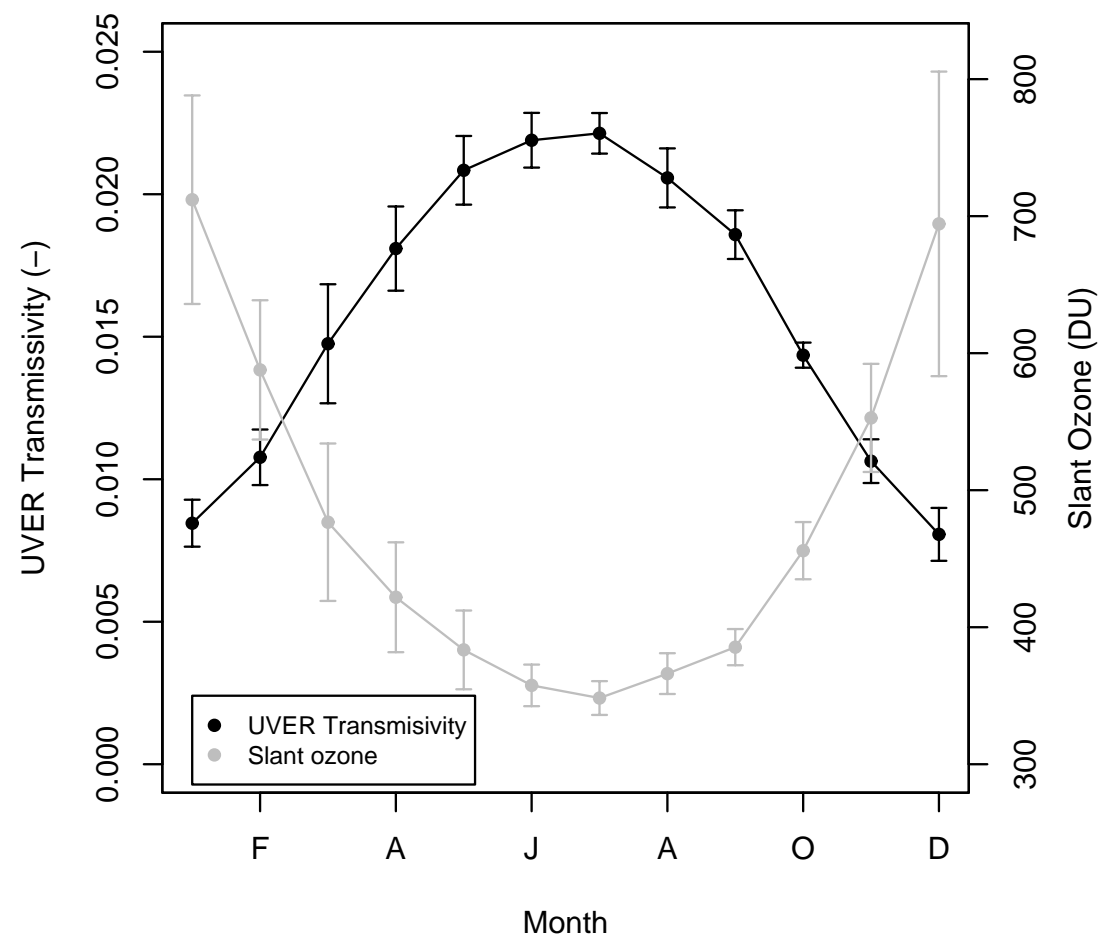

\section{Proposal of a new erythemal radiation amplification factor}

A. Serrano et al.

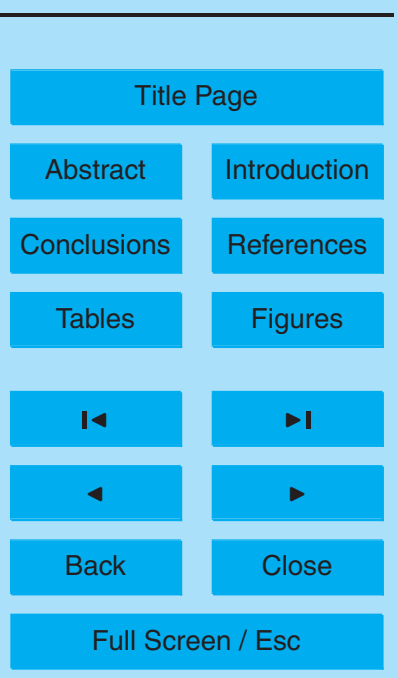

Fig. 3. The monthly mean evolution of slant ozone column and UVER transmisivity (only cloudfree conditions) at Badajoz station. 


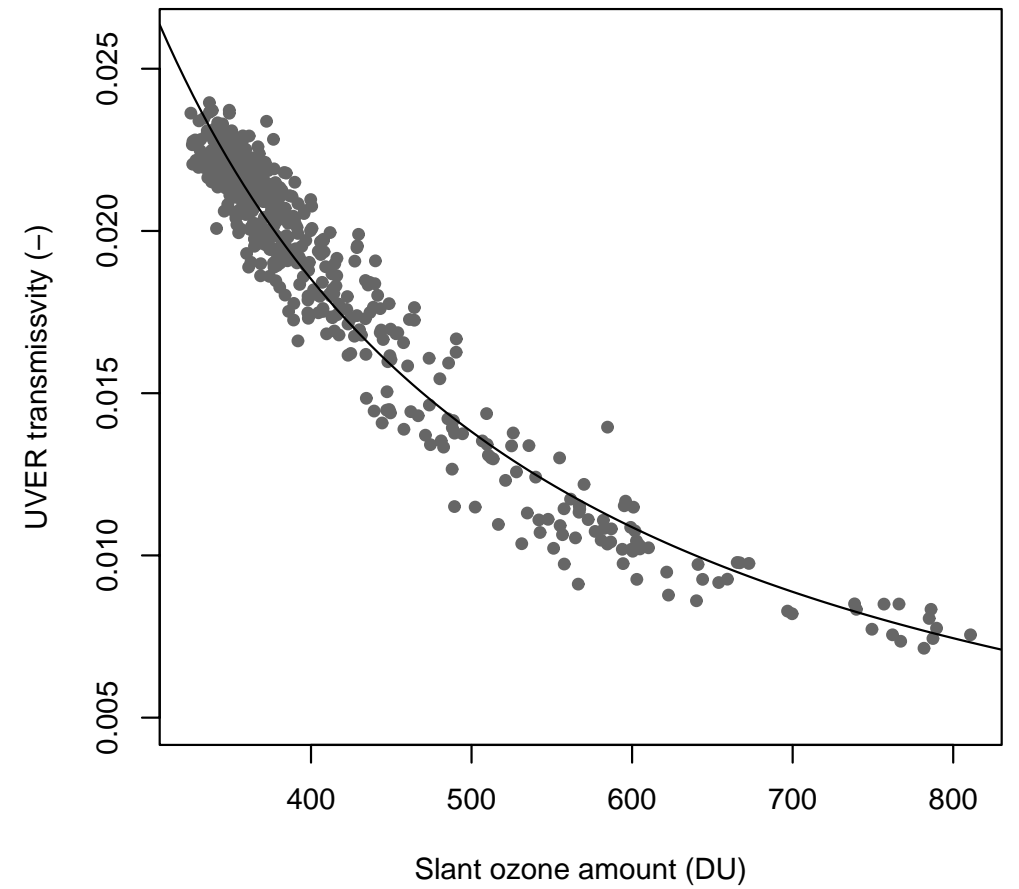

Fig. 4. Power law regression between UVER atmospheric transmissivities and slant ozone amount for clear cases at Badajoz from February 2001-December 2005. The coefficient of the power law function (1.31) gives the RAF value.

\section{ACPD}

$8,1089-1111,2008$

\section{Proposal of a new erythemal radiation amplification factor}

A. Serrano et al.

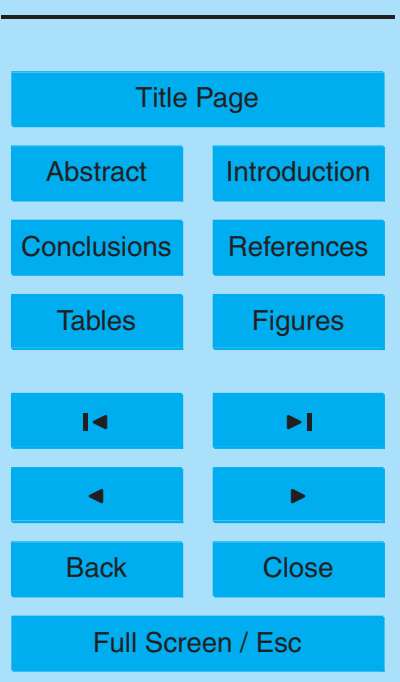

Printer-friendly Version

Interactive Discussion 


\section{ACPD}

8, 1089-1111, 2008

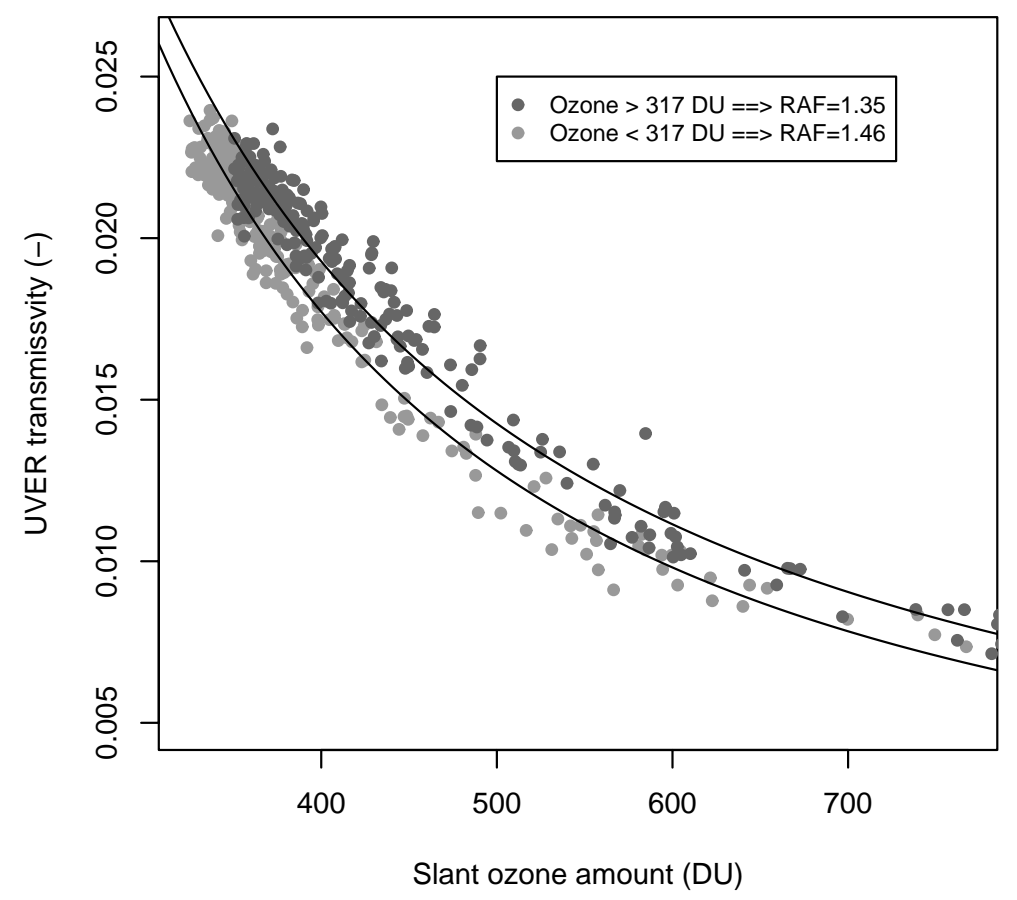

\section{Proposal of a new erythemal radiation amplification factor}

A. Serrano et al.

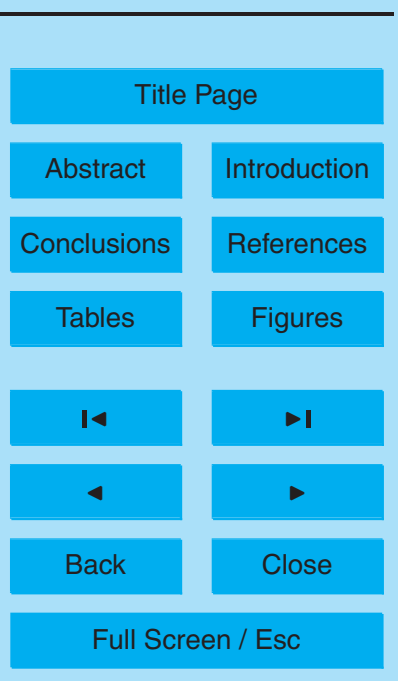

Fig. 5. Power law regression between UVER atmospheric transmissivities and slant ozone amount for two wide ozone interval.

Printer-friendly Version

Interactive Discussion 


\section{ACPD}

\section{8, 1089-1111, 2008}

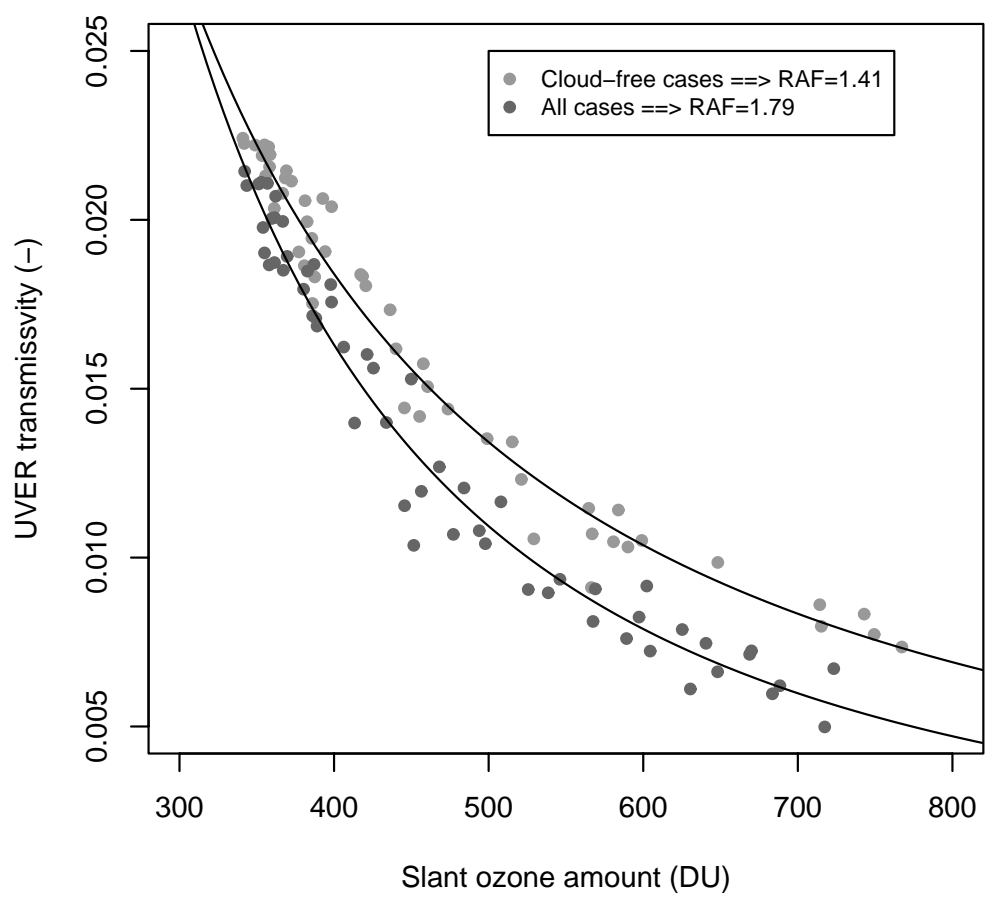

\section{Proposal of a new erythemal radiation amplification factor}

A. Serrano et al.

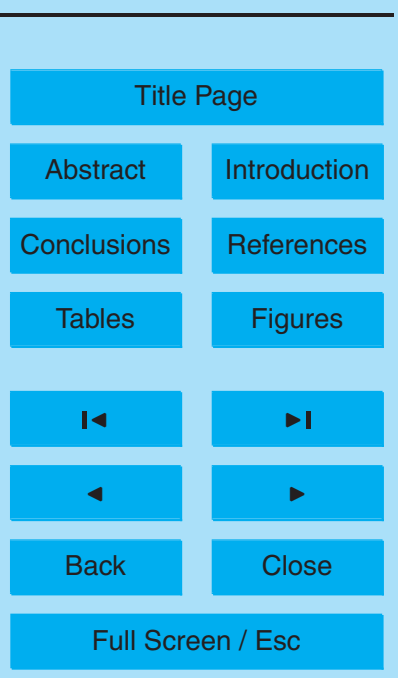

Fig. 6. Power law regression between monthly average of UVER atmospheric transmissivities and slant ozone column for cloud-free conditions and all cases. 